\title{
Removal of metoprolol from aqueous solutions by the activated carbon prepared from pine cones
}

\author{
Dariush Naghipour $^{1,2}$, Abdoliman Amouei $^{3,4^{*}}{ }^{\circledR}$, Kamran Taher Ghasemi $^{2}$, Kamran Taghavi $^{1,2}($ \\ ${ }^{1}$ Research Center of Health and Environment, Guilan University of Medical Sciences, Rasht, Iran \\ ${ }^{2}$ Department of Environmental Health, Guilan University of Medical Sciences, Rasht, Iran \\ ${ }^{3}$ Social Determinants of Health Research Center, Health Research Institute, Babol University of Medical Sciences, Babol, Iran \\ ${ }^{4}$ Environmental Health Research Center (EHRC), Health Research Institute, Babol University of Medical Sciences, Babol, Iran
}

\begin{abstract}
Background: Metoprolol (MTP) with its low biodegradability is one of the most dominant micropollutant in the effluent of wastewater treatment plants. The aim of this study was to investigate the removal of metoprolol from aqueous solutions by the activated carbon prepared from pine cones. Methods: The pine cones were activated using thermal activation method. Characteristics of the adsorbent were determined using Brunauer-Emmett-Teller (BET) and scanning electron microscopy (SEM). In this study, the influent of different parameters such as $\mathrm{pH}$, contact time, initial concentrations of metoprolol, adsorbent dose, temperature, adsorption isotherms, and kinetics were investigated. Results: The maximum removal efficiency of MTP (89.2\%) was obtained at $\mathrm{pH}=8.5$, adsorbent dose $=1.5 \mathrm{~g}$, contact time $=60 \mathrm{~min}$, and initial concentration $=50 \mathrm{mg} / \mathrm{L}$. By increasing the adsorbent dose, the removal efficiency also increased, but the adsorption capacity decreased, however, by increasing the initial concentration, the removal efficiency decreased, but the adsorption capacity increased. The isotherm experimental data for metoprolol was best fitted using the Langmuir model, and kinetic data were better described by pseudo-second-order kinetic model. The thermodynamic study indicated that the adsorption of MTP by the adsorbent was feasible, spontaneous, and endothermic.

Conclusion: MTP removal by the activated carbon prepared from pine cones showed that this natural adsorbent is appropriate for removal of metoprolol from aqueous solutions regarding cost, efficiency, and production method.

Keywords: Metoprolol, Adsorption, Pine cones, Isotherm, Kinetics, Thermodynamics

Citation: Naghipour D, Amouei A, Taher Ghasemi K, Taghavi K. Removal of metoprolol from aqueous solutions by the activated carbon prepared from pine cones. Environmental Health Engineering and Management Journal 2019; 6(2): 81-88. doi: 10.15171/EHEM.2019.09.
\end{abstract}

Article History:

Received: 16 December 2018

Accepted: 12 March 2019

ePublished: 8 April 2019

\section{Introduction}

The growth of the world population has created many problems including environmental pollution, especially pollution of water resources by wastewater that threaten human and environmental health $(1,2)$. Drugs are an essential and inseparable part of modern life that are used to treat human and animal diseases. In the last decade, many researchers studied the fate of drugs in the environment and their harmful effects on living organisms. These compounds are not biodegradable and more than $90 \%$ of them enters the environment without any changes $(3,4)$. Nowadays, the food and health industries discharge various pollutants into the environment and threaten human and environmental health. Therefore, it is necessary to remove these toxic materials from water, soil, and the environment $(5,6)$. The most important reason for studying and monitoring pharmaceutical pollutants in the environment is that they enter the food chain $(7,8)$. There are more than 4000 pharmaceutical compounds (only in Europe) having different chemical structures and various physical and chemical properties $(9,10)$. Studies have shown that pharmaceutical materials produced in drug manufacturing companies, the expired pharmaceuticals and medicines taken by humans and animals enter the environment (11-13). Because of their high water solubility, pharmaceuticals usually present in water resources and unfortunately, these compounds are not removed by the conventional water treatment systems $(14,15)$. Although the concentrations of the pharmaceuticals in drinking water are negligible, but these pollutants accumulate in the soils, plants, and animals and human body and may cause diseases in humans $(16,17)$. More than 80 different active pharmaceuticals have been detected in concentrations from $\mathrm{ppm}$ to $\mathrm{ppb}$ in the effluent of wastewater treatment plants, surface water, groundwater, and drinking water (18-20). 
Metoprolol (MTP) with the IUPAC name \{1-[4-(2-metoxy ethyl) phenoxy]-3-(propan-2-ylamino) propan-2-ol\} is one of the sympathetic blocking agents (Beta-blockers) taken for various cardiovascular diseases like high blood pressure, arrhythmia, and heart failure $(21,22)$. Betablockers are a group of medicines that cause vasodilation and reduce blood pressure by blocking the action of the noradrenaline and adrenaline hormones. At therapeutic doses, MTP controls cardiovascular system, reduces chest pain, and eventually, lowers blood pressure (2325). The chemical formula of this drug is $\mathrm{C}_{15} \mathrm{H}_{25} \mathrm{NO}_{3}$ and its molecular weight is $267.37 \mathrm{~g} / \mathrm{mol}$. The melting point, boiling point, and density of MTP are $52^{\circ} \mathrm{C}, 398.6^{\circ} \mathrm{C}$, and $194.9 \mathrm{~g} / \mathrm{mL}$, respectively. The half-life of this compound is $3-4$ hours and it has a $\mathrm{pk}_{\mathrm{a}}=9.5(26,27)$. MTP has a positive charge at neutral $\mathrm{pH}$ and is a moderate hydrophilic substance $(28,29)$. This drug increases its mobility in the presence of anionic surfactant (30). The solubility of this substance in water is $50 \mathrm{~g} / \mathrm{L}$ and its $\mathrm{LD}_{50}$ is $1.5 \mathrm{~g} / \mathrm{kg}$ (31). MTP with its low biodegradability is one of the most dominant micro-pollutant in the effluent of wastewater treatment plants and surface waters even in the drinking waters in the world $(32,33)$. MTP concentrations in drinking water have been reported from $3 \mathrm{ng}$ to $4.9 \mu \mathrm{g}$ (34) (Figure 1).

Different studies have suggested that biological treatments are not appropriate for removal of the pharmaceutical pollutants, and new methods like advanced oxidation technology and adsorption processes are appropriate to degrade and remove them from the polluted water $(35,36)$. Adsorption process has the highest removal efficiency for removal of organic compounds from industrial wastewater (37). It is easy to design and operate, it does not produce toxic materials, and is cost-effective $(33,38)$. Therefore, adsorption is widely employed as an effective and costeffective method to remove organic materials from water resources. Various adsorbents like activated carbon, natural and agricultural wastes, waste minerals, and soils have been tested for removal of organic compounds (36). Among these different adsorbents, activated carbon is the most widely employed compound for removal of organic pollutants from wastewater and contaminated water because it has high porosity coefficient, large specific surface area (SSA), and suitable adsorption capacity (37). The adsorption efficiency of activated carbon depends on the adsorbent and its characteristics and also the environmental conditions of the wastewater. In the present study, MTP removal from aqueous solutions by the activated carbon prepared from pine cones and the parameters affecting adsorption process were investigated.

\section{Materials and Methods}

This applied research was conducted in a laboratory on a batch scale. Pine cones were used to prepare activated carbon for removal of MTP from contaminated water through adsorption process. The parameters affecting<smiles>COCCc1ccc(OCC(O)CNC(C)C)cc1</smiles>

Figure 1. Metoprolol molecular structure.

adsorption process including initial concentration of MTP, adsorbent dose, solution $\mathrm{pH}$, reaction time, and temperature were investigated.

Preparation of the activated carbon from pine cones To prepare the main material in the adsorption process, pine cones were first ground and washed several times with distilled water. The powder was placed in a desiccator for 24 hours to dry and then, was carbonized at $400^{\circ} \mathrm{C}$ for 2 hours followed by $\mathrm{CO}_{2}$ activation at $800^{\circ} \mathrm{C}$. Morphology of the surface area of the adsorbent was studied using scanning electron microscopy (SEM), and the micropore surface, micropore volume, and micropore size were measured based on the Brunauer-Emmett-Teller (BET) model using nitrogen gas adsorption-desorption.

Preparation of the stock solution of MTP

MTP tartrate salt (98\%) was purchased from Kowsar Pharmaceutical Company (Tehran, Iran). To prepare the stock solution $(1000 \mathrm{mg} / \mathrm{L}), 1 \mathrm{~g}$ of this material was dissolved in 1 liter of double-distilled water. The $\mathrm{C}_{1} \mathrm{~V}_{1}$ $=\mathrm{C}_{2} \mathrm{~V}_{2}$ equation was used to prepare the required MTP concentrations. 0.1 M hydrochloric acid and sodium hydroxide solutions were used to adjust the $\mathrm{pH}$ of MTP solution.

Determination of the $\mathrm{pH}_{\mathrm{pzc}}$ of the adsorbent prepared from pine cones

The $\mathrm{pH}_{\mathrm{pzc}}$ of the prepared activated carbon was measured using direct $\mathrm{pH}$ measurement method. Fifty $\mathrm{ml}$ of $0.1 \mathrm{M}$ $\mathrm{NaCl}$ solution was poured into each $150 \mathrm{~mL}$ Erlenmeyer flask and $\mathrm{pH}$ was adjusted to different $\mathrm{pH}$ range (2-12) using $\mathrm{NaOH}$ and $\mathrm{HCl}$. The adsorbent $(0.04 \mathrm{~g})$ was then added to each solution, the Erlenmeyer flasks were closed with screw caps and stirred for 48 hours using an electric stirrer, and the final $\mathrm{pH}$ was measured and its curve was drawn against the initial $\mathrm{pH}$. The point where the bisector intersected the curve, was designated as the $\mathrm{pH}_{\mathrm{pzc}}$ of the activated carbon.

Design of the laboratory system for adsorption studies In each experiment, $50 \mathrm{ml}$ of MTP solution at each concentration was poured into an Erlenmeyer flask, and $\mathrm{pH}$ was adjusted using $0.1 \mathrm{~N} \mathrm{HCl}$ and $\mathrm{NAOH}$. Specific amounts of the prepared activated carbon were added to the solutions and the solutions were stirred at $150 \mathrm{rpm}$. Using the standard curve and a DR5000 
spectrophotometer at $221 \mathrm{~nm}$, the concentration of the remaining MTP in each solution was determined $(33,34)$. Temperature of the solutions was measured using a mercury thermometer. All experiments were performed twice to make sure of the results and, in the case of any uncertainty, the experiments were repeated for the third time. To study the total parameters, 72 samples were required. The following relations were employed to determine the amounts of MTP adsorbed on the activated carbon in terms of adsorption percentage and adsorption capacity.

$q_{e}=\frac{\left(C_{0}-C_{t}\right)}{M} V$

$R=\frac{\left.C_{0}-C_{t}\right)}{C_{0}} \times 100$

Where $C_{0}$ is the initial concentration of MTP $(\mathrm{mg} / \mathrm{L}), C_{t}$ is the concentration of MTP at time of $t(\mathrm{~min}), V$ is the volume of solution (L), and $M$ is the weight of adsorbent (g).

\section{Results}

Physical characteristics of the adsorbent

The micropore surface area, micropore volume, and diameter of the prepare Dbiochar were $63.2 \mathrm{~cm}^{2} / \mathrm{g}$, $0.532 \mathrm{~cm}^{3} / \mathrm{g}$, and $2.2 \mathrm{~nm}$, respectively. SEM image of the molecular structure of the biochar prepared from the pine cones is presented in Figure 2. High-hollow fibers of this biochar indicate that the adsorbent prepared is appropriate for removal of different pollutants in the adsorption process (Figure 2).

Determination of the point of zero charge $\left(\mathrm{pH}_{\mathrm{pzc}}\right)$

Determination of the $\mathrm{pH}_{\mathrm{pzc}}$ of adsorbents is important for removal of pollutants by adsorption process. In this study, $\mathrm{pH}_{\mathrm{pzc}}$ of the biochar was used to estimate the effect of $\mathrm{pH}$ on the MTP adsorption rate. $\mathrm{PH}_{\mathrm{pzc}}$ of the pine cones biochar was determined 6.5 (Figure 3 ).

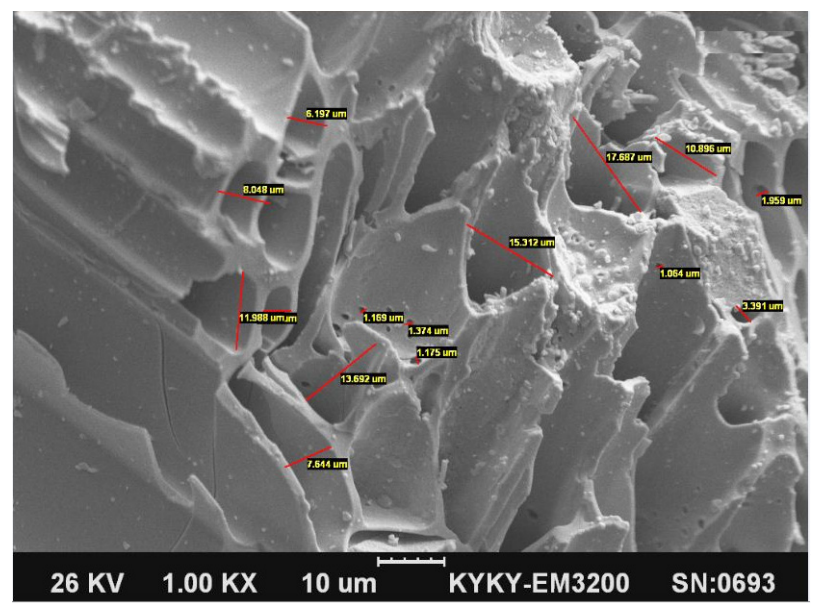

Figure 2. SEM image of the pine cones biochar before MTP adsorption.
Effects of solution $\mathrm{pH}$ on the MTP removal efficiency Effects of $\mathrm{pH}$ in the range of 2-12, were studied to determine the optimum $\mathrm{pH}$ for achieving the highest efficiency of MTP adsorption on the prepared activated carbon. Figure 4 shows that the highest MTP removal efficiency (89.2\%) was achieved at $\mathrm{pH}$ 8.5. The removal efficiency of MTP decreased at pH values of 2 to 6.5, but increased at $\mathrm{pH} 6.5$ to 9.5 and again decreased at $\mathrm{pH}$ more than 9.5.

Effects of adsorbent dosage on MTP removal efficiency Effects of adsorbent doses (0.1-2 g/L) were studied to determine the optimum dose for achieving suitable adsorption by the prepared activated carbon. Figure 5 indicates the MTP removal percentages at various adsorbent doses. MTP removal efficiency at doses of 0.1 , 0.2 , and $0.5 \mathrm{~g} / \mathrm{l}$ was 39,51 , and $74 \%$, respectively. The maximum removal of MTP (90\%) occurred at adsorbent dose of $2.5 \mathrm{~g} / \mathrm{L}$ (Figure 5). In this study, the reasonable and economic removal of MTP (89.2\%) was determined at adsorbent dose of $1.5 \mathrm{~g} / \mathrm{L}$. At adsorbent doses more than $2.5 \mathrm{~g} / \mathrm{L}$ (Figure 5), the removal efficiency of MTP was not increased more.

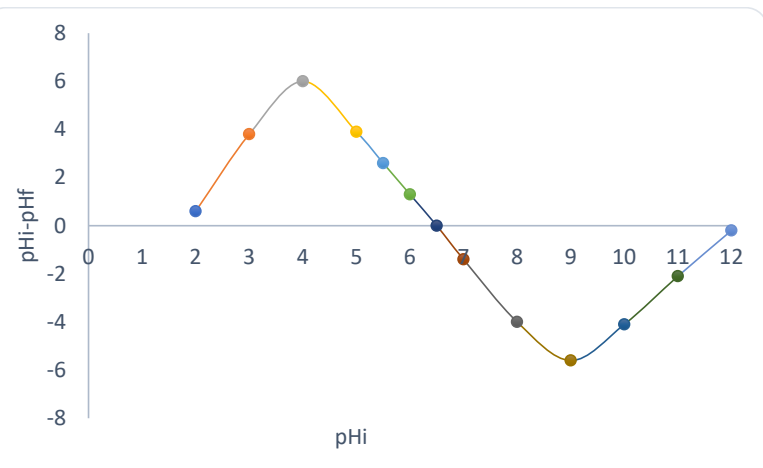

Figure 3. Determination of the point of zero charge of the pine cones biochar.

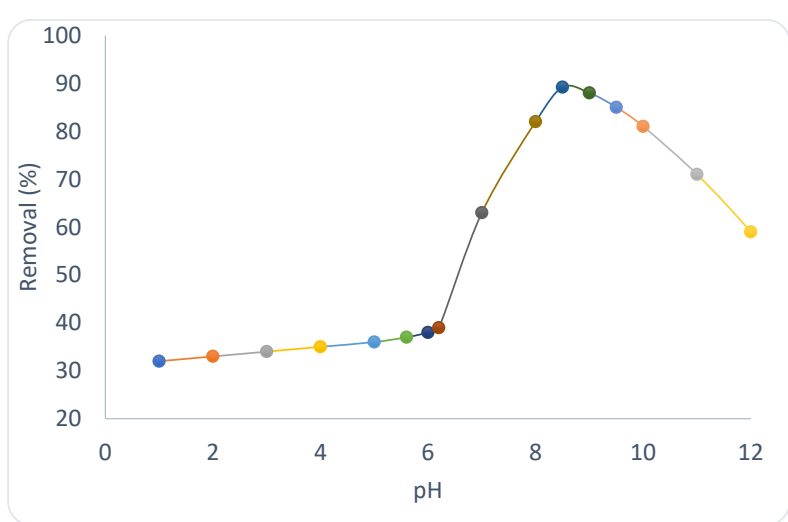

Figure 4. Effect of $\mathrm{pH}$ of solution on MTP $(\mathrm{C}=50 \mathrm{mg} / \mathrm{L}$; adsorbent dose= $1.5 \mathrm{~g} / \mathrm{l} ;$ time $=60 \mathrm{~min} ; \mathrm{T}=25^{\circ} \mathrm{C}$ ). 


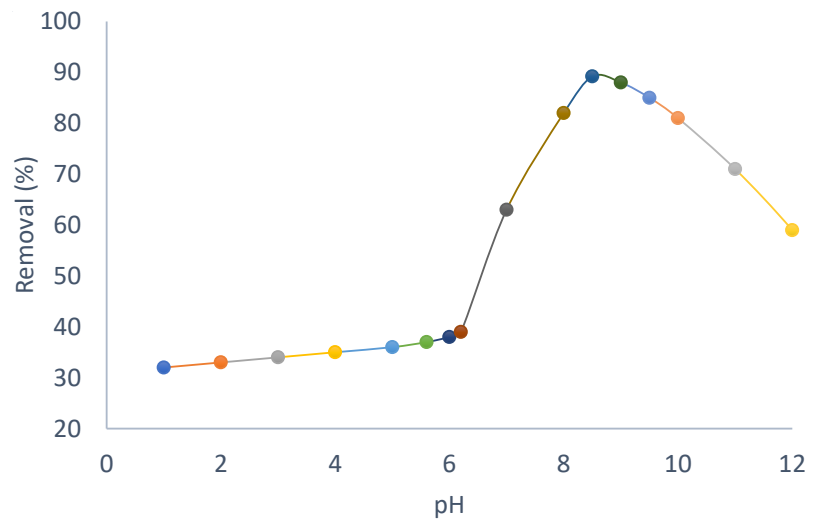

Figure 5. E. ffect of adsorbent dose on the MTP removal $(C=50 \mathrm{mg} / \mathrm{L} ; \mathrm{pH}=$ 8.5; time $=60 \mathrm{~min} ; \mathrm{T}=25^{\circ} \mathrm{C}$ ).

Effects of initial concentration and reaction time on the MTP removal efficiency

Figure 6 demonstrates the effects of various MTP concentrations $(10,50$, and $100 \mathrm{mg} / \mathrm{L})$ on its removal under the specified conditions. Under these conditions $\left(\mathrm{pH}=8.5\right.$, adsorbent dose $=1.5 \mathrm{~g} / \mathrm{L}$, temperature $\left.=25^{\circ} \mathrm{C}\right)$ and initial MTP concentration of $10 \mathrm{mg} / \mathrm{L}$, complete MTP removal (99\%) was achieved at contact time of 10 minutes. At the initial MTP concentration of 50 and $100 \mathrm{mg} / \mathrm{L}$, removal efficiency reached 89.2 and $62.3 \%$, respectively, after 60 minutes. According to Figure 6, at concentrations of 50 and $100 \mathrm{mg} / \mathrm{L}$, the percentage of MTP removal over a period of more than 60 minutes was not increased more.

Effects of temperature on MTP adsorption kinetics and thermodynamics parameters

MTP adsorption efficiency was determined at temperatures of 10 to $60^{\circ} \mathrm{C}$ under the specified conditions (Figure 7). According to this figure, with increase of temperature from 10 to $60^{\circ} \mathrm{C}$, MTP removal efficiency was increased from 85.5 to $91.9 \%$. The highest removal efficiency $(91.9 \%)$ was observed at temperature $50^{\circ} \mathrm{C}$, but the removal efficiency was not increased more at temperatures higher than $50^{\circ} \mathrm{C}$.

Table 1 shows the contents of $\Delta H, \Delta S$, and $\Delta \mathrm{G}$ at 10 to $40^{\circ} \mathrm{C}$. As shown in this table, the contents of $\Delta \mathrm{H}, \Delta \mathrm{S}$, and $\Delta \mathrm{G}$ at $10^{\circ} \mathrm{C}$ were $26.27 \mathrm{KJ} / \mathrm{mol}, 122.5 \mathrm{~J} / \mathrm{mol}^{\circ} \mathrm{K}^{\circ}$, and -8.61 $\mathrm{KJ} / \mathrm{mol}$, respectively.

MTP adsorption equilibrium and equilibrium isotherm on the pine cones

In this research, MTP adsorption equilibrium and equilibrium isotherm at various MTP concentrations under the specified experimental conditions were investigated. MTP removal at its initial concentration of $50 \mathrm{mg} / \mathrm{L}$ reached equilibrium after 6 hours, and at initial concentration of $200 \mathrm{mg} / \mathrm{L}$, its removal efficiency declined to $66 \%$ (Figure $8 \mathrm{a}$ ). However, under the same conditions, adsorption capacity increased from 62 to $165 \mathrm{mg} / \mathrm{g}$ with increase of MTP concentration (Figure 8b). In this study,

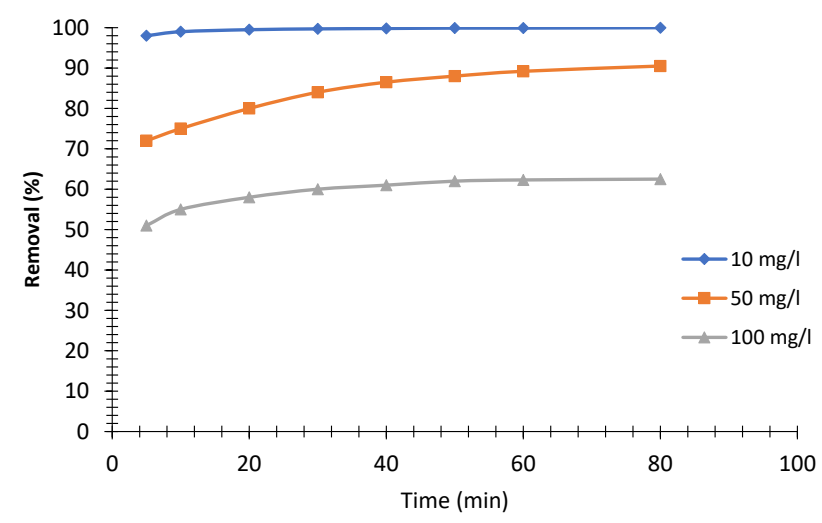

Figure 6. Effect of the initial concentrations and contact time on the MTP removal (adsorbent dose $=1.5 \mathrm{~g} / \mathrm{L} ; \mathrm{pH}=8.5 ; \mathrm{T}=25^{\circ} \mathrm{C}$ ).

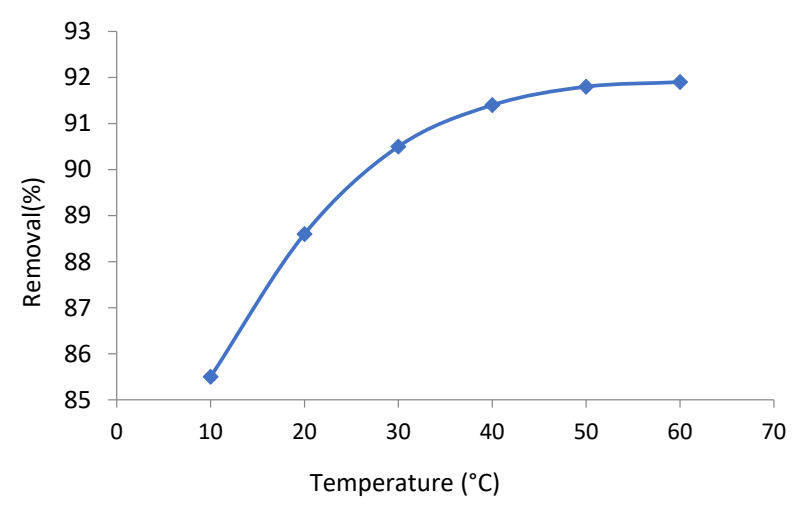

Figure 7. Effect of temperature on the MTP removal $(C=50 \mathrm{mg} / \mathrm{L} ; \mathrm{pH}=8.5$; adsorbent dose $=1.5 \mathrm{~g} / \mathrm{L}$; contact time $=60 \mathrm{~min}$ ).

the saturated adsorption capacity of MTP by the biochar was determined $179 \mathrm{mg} / \mathrm{g}$ at MTP concentration of 200 $\mathrm{mg} / \mathrm{L}$ in 6 hours.

Langmuir model is credible for single-layer adsorption on the adsorbent surface with limited and homogeneous adsorption sites. Langmuir isotherm is defined by the following equation:

$q_{e}=\frac{q_{\max } \times K_{L} \times C_{e}}{1+K_{L} \times C_{e}}$

Where $q_{\max }$ is the maximum adsorption capacity (mg $\left.\mathrm{g}^{-1}\right), C_{e}$ is the equilibrium concentration $\left(\mathrm{mg} \mathrm{L}^{-1}\right), q_{e}$ is the equilibrium adsorption capacity $\left(\mathrm{mg} \mathrm{g}^{-1}\right)$, and $K_{L}$ is the Langmuir equilibrium constant $\left(\mathrm{L} \mathrm{mg}^{-1}\right)$.

The Freundlich isotherm is an empirical and valid equation for the adsorption that takes place on the heterogeneous surfaces. The Freundlich isotherm model can be presented by Eq. (4):

$q_{e}=K_{F} \times C_{e}^{1 / n_{F}}$

Where $K_{F}$ is the Freundlich equilibrium constant $\left[\mathrm{mg} \mathrm{g}^{-1} \times\right.$ $\left.\left(\mathrm{mg} \mathrm{L}^{-1}\right)_{\mathrm{F}}^{-1 / \mathrm{n}}\right]$ and $n_{F}$ is the dimensionless exponent of the 
Table 1. Thermodynamic parameters of MTP adsorption

\begin{tabular}{|c|c|c|c|c|c|c|c|c|c|}
\hline$q_{e}$ & $c_{e}(m g / L)$ & $\mathbf{k}_{\mathrm{d}}$ & $1 / \mathrm{t}$ & $\operatorname{Ln} k_{d}$ & $T\left({ }_{k}\right)$ & $\mathrm{T}\left({ }^{\circ} \mathrm{C}\right)$ & $\Delta \mathrm{S}\left(\mathrm{J} / \mathrm{mol} . \mathrm{K}^{\circ}\right)$ & $\Delta \mathrm{H}(\mathrm{kJ} / \mathrm{mol})$ & $\Delta \mathrm{G}(\mathrm{kJ} / \mathrm{mol})$ \\
\hline 60.2 & 1.53 & 39 & 0.0035 & 3.66 & 283 & 10 & 122.5 & 26.27 & -8.61 \\
\hline 61 & 1.1 & 55 & 0.0034 & 4 & 293 & 20 & - & - & 9.74- \\
\hline 61.6 & 1.8 & 77 & 0.0033 & 4.32 & 303 & 30 & - & - & $10.98-$ \\
\hline 62 & 0.6 & 103 & 0.0032 & 4.6 & 313 & 40 & - & - & $11.97-$ \\
\hline
\end{tabular}

Freundlich model. The MTP adsorption isotherm results are presented in Figures 9 and 10.

\section{Adsorption kinetics of MTP}

To investigate the effective factors on the reaction rate and the mechanisms for controlling the adsorption process, the kinetics evaluation is necessary. The MTP adsorption kinetics was determined using pseudo-first-order (PFO) and pseudo-second-order (PSO) models to accord the experimental data.

The liner form of the PFO kinetic models can be presented by Eq. (5):

$$
\operatorname{Ln}\left(q_{e}-q_{t}\right)=\operatorname{Ln} q_{e}-K_{1} t
$$

The PSO model is based on the chemisorption on the adsorbent. The liner form of the PSO model can be expressed by the following equation:

$\frac{t}{q_{t}}=\frac{1}{k_{2} q_{e}{ }^{2}}+\frac{1}{q_{e}}$
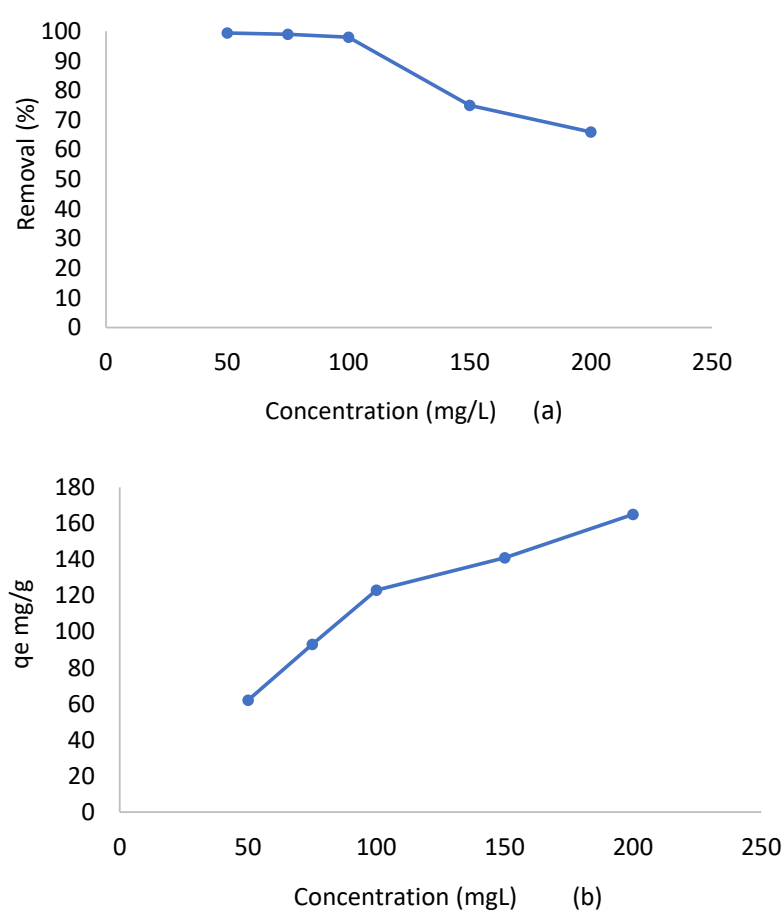

Figure 8. Adsorption efficiency (a) and capacity (b) of 6-hour equilibrium of MTP on the pine cone biochar.

\section{Discussion}

According to the results, the adsorbent prepared from pine cones contains appropriate structural characteristics for adsorption process. The micropore surface area, micropore volume, and diameters of the prepared biochar were $63.2 \mathrm{~cm}^{2} / \mathrm{g}, 0.532 \mathrm{~m}^{3} / \mathrm{g}$, and $2.2 \mathrm{~nm}$, respectively. High-hollow fibers of this biochar indicate that $t$ he adsorbent prepared is appropriate for removal of different pollutants in the adsorption process. In a study b y Mohseni et al, clinoptilolite zeolite was used for removal of dexamethasone from aqueous solutions. The SSA and pore volume of this zeolite were $43.91 \mathrm{~cm}^{2} / \mathrm{g}$ and 0.1717 $\mathrm{m}^{3} / \mathrm{g}$, respectively (34).

In this study, the point of zero charge $\left(\mathrm{pH}_{\mathrm{pzc}}\right)$ of the

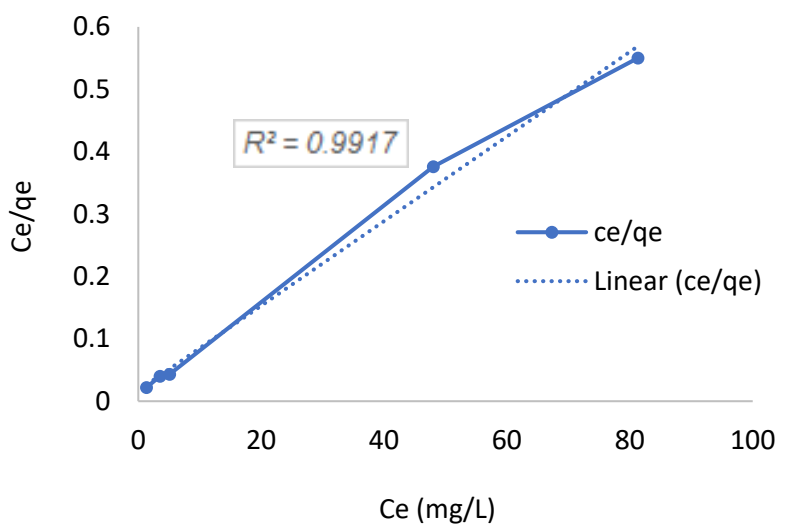

Figure 9. Langmuir isotherm of MTP on the pine cones biochar

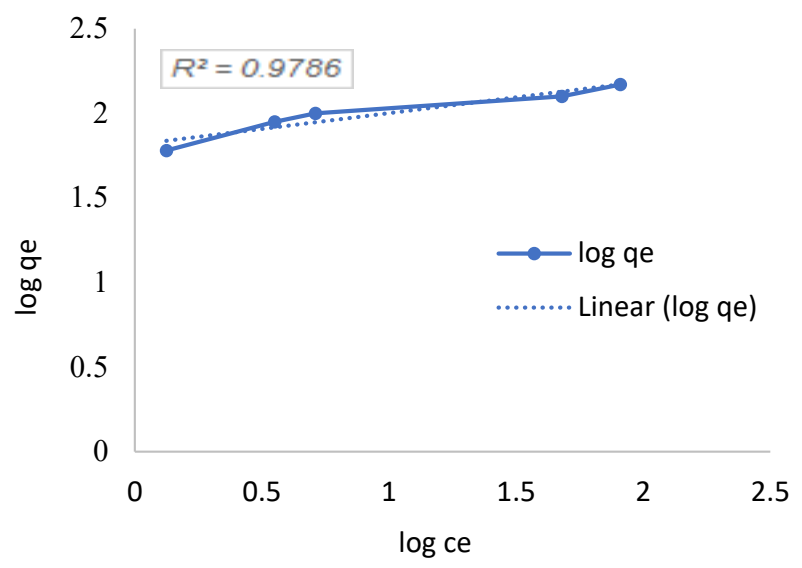

Figure 10. Freundlich isotherm of MTP on the pine cones biochar. 
Table 2. The MTP adsorption kinetics on the pine cones biochar

\begin{tabular}{|c|c|c|c|c|c|c|}
\hline \multirow{2}{*}{ (Lmg) $C_{0}$} & \multicolumn{3}{|c|}{ Pseudo -first- order } & \multicolumn{3}{|c|}{ Pseudo -second-order } \\
\hline & qe $(\mathrm{mg} / \mathrm{g})$ & $K_{1}\left(\min ^{-1}\right)$ & $\mathbf{R}_{2}$ & qe $(\mathrm{mg} / \mathrm{g})$ & $\mathrm{K}_{2}\left(\mathrm{mg} / \mathrm{g} \cdot \mathrm{min}^{-1}\right)$ & $\mathbf{R}_{2}$ \\
\hline 50 & 12.65 & 0.0467 & 0.927 & 23.25 & 0.0048 & 0.991 \\
\hline 100 & 18.31 & 0.0112 & 0.905 & 38.72 & 0.0026 & 0.972 \\
\hline
\end{tabular}

prepared biochar was determined 6.5. The $\mathrm{pHpzc}$ is a point where the potential charge on the surface of an adsorbent is zero. The $\mathrm{pH}_{\mathrm{pzc}}$ is used to estimate the effect of $\mathrm{pH}$ on the MTP adsorption rate (31). The removal efficiency of MTP decreased at $\mathrm{pH}$ values of 2- 6.5, but increased at $\mathrm{pH}$ range of 6.5 to 9.5 and again decreased at $\mathrm{pH}$ more than 9.5. At $\mathrm{pH}$ range of 2 to $6.5\left(\mathrm{pH}_{\text {solution }}<\mathrm{pH}_{\mathrm{pzc}}\right)$, positive functional groups and $\mathrm{H}^{+}$ions in MTP molecules moves to the adsorbent surface and in this condition, the adsorbent surface is positive. The presence of positive functional groups in the MTP structure and the effect of positive charge of the adsorbent surface will increase the electrostatic repulsion between MTP molecules and the adsorbent surface and as a result, reduces the removal efficiency of MTP (33). Furthermore, it was observed that removal efficiency of MTP improved when $\mathrm{pH}$ increased from 6.5 to 9.5. This phenomenon may be related to the presence of many positively charged functional groups especially $\mathrm{H}^{+}$in the structure of MTP $\left(\mathrm{pk}_{\mathrm{a}}=9.5\right)$ and to the negative charge on the surface of the adsorbent (positive charge movement from the adsorbent surface to the MTP solution) caused by the $\mathrm{pH}_{\mathrm{pzc}}$ of the adsorbent $\left(\mathrm{pH}_{\mathrm{pzc}}>\mathrm{pH}_{\text {solution }}\right)(31,34)$. At alkaline $\mathrm{pH}$ values of the solution $(\mathrm{pH}>9.5)$, the presence of negative functional groups in the MTP solution (carboxyl and hydroxyl ions) and negative charge of adsorbent surface will increase the electrostatic repulsion between MTP molecules and the adsorbent surface and as a result, reduces the removal efficiency of MTP (32).

In this study, the reasonable and economic removal of MTP (89.2\%) was obtained at $1.5 \mathrm{~g} / \mathrm{L}$ adsorbent dose. This relatively good efficiency, given the very small amount of the adsorbent, was due to the high SSA of the prepared activated carbon and the presence of many micropores on its inner structure $(33,34)$. At higher doses of the adsorbent, removal efficiency was slightly increased when further portions of the adsorbent $(0.2 \mathrm{~g} / \mathrm{L})$ were added because the SSA, and hence, the number of functional groups increased and removal efficiency improved when more activated carbon was used until the removal efficiency for $2.5 \mathrm{~g} / \mathrm{L}$ of the adsorbent reached $90 \%$. Removal percentage declined at higher adsorbent doses (more than $2.5 \mathrm{~g} / \mathrm{L}$ ) because there was less MTP in the solution and also the micropores on the surface of the carbon were occupied (32). According to this study, at concentrations of 50 and $100 \mathrm{mg} / \mathrm{L}$, the percentage of MTP removal over a period of more than 60 minutes did not increase more. This was because, given the high concentrations, after a certain period, the empty sites on the carbon surface were occupied and the removal percentage of MTP decreased (31).

According to this study, the saturated adsorption capacity of MTP by the biochar in 6 hours at MTP concentration of $200 \mathrm{mg} / \mathrm{L}$ was $179 \mathrm{mg} / \mathrm{g}$. MTP removal efficiency increased from 85.5 to $91.9 \%$ with increase of temperature from 10 to $60^{\circ} \mathrm{C}$. So, the removal efficiency of MTP increased with increase of temperature, and the adsorption process is an endothermic reaction (30). The highest removal efficiency $(91.9 \%)$ was observed at temperature of 40 to $50^{\circ} \mathrm{C}$, but removal efficiency did not increase more at temperatures higher than $50^{\circ} \mathrm{C}$. With increase of the optimum solution temperature, the velocity of MTP molecules into the adsorbent micropores also increases (31). Considering the negative value of $\Delta \mathrm{G}(-11.970$ to $-8.611 \mathrm{Kj} / \mathrm{mol}$ ), it can be concluded that the adsorption process was spontaneous. In addition, the positive value of $\Delta \mathrm{S}(122.5 \mathrm{~J} / \mathrm{mol} . \mathrm{K})$ shows that there was an equilibrium state at the solid-liquid interface on the adsorbent surface. In other words, removal efficiency improved with increase of the temperature at the solid-liquid interface during the adsorption process. This phenomenon could be due to slight changes in the structure of the adsorbate and the adsorbent at various temperatures (29).

In this research, MTP adsorption equilibrium and equilibrium isotherm at various MTP concentrations under the specified experimental conditions were investigated. The increase of adsorption capacity by increasing the MTP concentration under the specified experimental conditions can be described by the fact that increasing the MTP concentrations led to higher mass transfer of MTP molecules onto the adsorbent, and as a result, the adsorption capacity increased (31).

An adsorption isotherm describes the relationship between the amount of adsorbate adsorbed on the adsorbent and the dissolved adsorbate in the liquid at equilibrium. The Langmuir and Freundlich isotherms are used to explain the equilibrium adsorption (37). According to the results of this study, the correlation coefficient for the Langmuir isotherm model $\left(\mathrm{R}^{2}=0.992\right)$ is higher than that for the Freundlich isotherm $\left(\mathrm{R}^{2}=0.979\right)$. So, in this study, the Langmuir isotherm model is more appropriate than the Freundlich isotherm for explaining the equilibrium adsorption. The kinetics is effective for understanding the reaction speed in the adsorption process (38). For this reason, kinetic parameters play an important role in designing the adsorption process. According to this study, 
the correlation coefficients for the PSO kinetic model at concentrations of 50 and $100 \mathrm{mg} / \mathrm{L}$ were 0.991 and 0.972 , respectively, while the correlation values for the $\mathrm{PFO}$ were 0.927 and 0.905 , respectively.

\section{Conclusion}

In this study, the pine cones as natural raw materials were prepared for removal of MTP from the aqueous solutions. The characteristics of the adsorbent were investigated by various techniques and also, the effects of several parameters on the adsorption of MTP on the pine cones biochar were investigated. In this study, the optimum adsorbent dosage was obtained $1.5 \mathrm{~g}$ and the MTP adsorption on the biochar was found to be optimal at $\mathrm{pH}=8.5$. The regression coefficients obtained through different isotherm models show that Langmuir isotherm is in accordance with the equilibrium data. The adsorption kinetics was better described by PSO kinetic model. The thermodynamic studies showed that the adsorption of MTP on the pine cones biochar is a physical, endothermic, and spontaneous reaction. According to the results, the biochar produced from pine cones is an efficient adsorbent for the treatment of pharmaceutical wastewater containing beta-blocker compounds.

\section{Acknowledgments}

The authors would like to thank all those who contributed to this work especially Guilan University of Medical Sciences that supported this study.

\section{Ethical issues}

The authors certify that this manuscript is the original work of the authors, all data collected during the study is presented in this manuscript, and no data from the study has been or will be published separately.

\section{Competing interests}

The authors declare that they have no conflict of interests.

\section{Authors' contributions}

All authors contributed equally and participated in the data collection, analysis, and interpretation. All authors critically reviewed, refined, and approved the manuscript.

\section{References}

1. Ehrampoush M, Hossein Shahi D, Ebrahimi A, Ghaneian M, Lotfi M, Ghelmani S, et al. Evaluation of the efficiency of sub-surface constructed wetland methods in wastewater treatment in Yazd city in 2011. Tolooe Behdasht 2013; 12(1): 33-43. [In Persian].

2. Sallmann AR. The history of diclofenac. Am J Med 1986; 80(4B): 29-33.

3. Sayadi AR, Asadpour M, Shabani Z, Sayadi MH. Pharmaceutical pollution of the eco-system and its detrimental effects on public health. Journal of Rafsanjan University of Medical Sciences 2012; 11(3): 269-84. [In Persian].
4. Amooey AA, Amouei A, Tashakkorian H, Mohseni SN. Performance of clinoptilolite zeolite in removal of dexamethasone from aqueous solutions. Journal of Mazandaran University of Medical Sciences 2016; 25(133): 128-37. [In Persian].

5. Qasim SR, Motley EM, Zhu G. Water works engineering: planning, design, and operation. Prentice Hall; 2000. p. 209-12.

6. Lin $\mathrm{AY}, \mathrm{Yu} \mathrm{TH}$, Lateef SK. Removal of pharmaceuticals in secondary wastewater treatment processes in Taiwan. J Hazard Mater 2009; 167(1-3): 1163-9. doi: 10.1016/j. jhazmat.2009.01.108.

7. Turkdogan FI, Yetilmezsoy K. Appraisal of potential environmental risks associated with human antibiotic consumption in Turkey. J Hazard Mater 2009; 166(1): 297 308. doi: 10.1016/j.jhazmat.2008.11.012.

8. Wise R. Antimicrobial resistance: priorities for action. J Antimicrob Chemother 2002; 49(4): 585-6.

9. Abdollahiasl A, Kebriaeezadeh A, Nikfar S, Farshchi A, Ghiasi G, Abdollahi M. Patterns of antibiotic consumption in Iran during 2000-2009. Int J Antimicrob Agents 2011; 37(5): 489-90. doi: 10.1016/j.ijantimicag.2011.01.022.

10. Bellona C, Drewes JE, Xu P, Amy G. Factors affecting the rejection of organic solutes during NF/RO treatment--a literature review. Water Res 2004; 38(12): 2795-809. doi: 10.1016/j.watres.2004.03.034.

11. Leiros HK, Kozielski-Stuhrmann S, Kapp U, Terradot L, Leonard GA, McSweeney SM. Structural basis of 5-nitroimidazole antibiotic resistance: the crystal structure of NimA from Deinococcus radiodurans. J Biol Chem 2004; 279(53): 55840-9. doi: 10.1074/jbc.M408044200.

12. Sheikh Mohammadi A, Sardar M. The removal of penicillin $\mathrm{G}$ from aqueous solutions using chestnut shell modified with H2SO4: Isotherm and kinetic study. Iran J Health Environ 2013; 5(4): 497-508.

13. Karimi A, Mohajeri A, Jebreili Jolodar A, Rashidi AM, Forsat K. solvent pre-treated effects of carbon nanotubesupported cobalt catalysts on activity and selectivity of Fischer-Tropsch synthesis. Journal of Petroleum Science and Technology 2016; 6(1): 14-27. doi: 10.22078/ jpst.2016.565.

14. Ioannidou OA, Zabaniotou AA, Stavropoulos GG, Islam MA, Albanis TA. Preparation of activated carbons from agricultural residues for pesticide adsorption. Chemosphere 2010; 80(11): 1328-36. doi: 10.1016/j. chemosphere.2010.06.044.

15. Kakavandi B, Jonidi jafari A, Rezaei Kalantary R, Nasseri S, Ameri A, Esrafily A. Synthesis and properties of Fe3O4activated carbon magnetic nanoparticles for removal of aniline from aqueous solution: equilibrium, kinetic and thermodynamic studies. Iranian J Environ Health Sci Eng 2013; 10(1): 19. doi: 10.1186/1735-2746-10-19.

16. Mousavi SG, Khosravi R. Removal of cyanide from wastewater by adsorption onto pistachio hull wastes: parametric experiments, kinetics and equilibrium analysis. J Hazard Mater 2010; 183(1-3): 724-30. doi: 10.1016/j. jhazmat.2010.07.086.

17. Hamadi NK, Chen XD, Farid MM, Lu MGQ. Adsorption kinetics for the removal of chromium(VI) from aqueous solution by adsorbents derived from used tyres and 
sawdust. Chem Eng J 2001; 84(2): 95-105. doi: 10.1016/ S1385-8947(01)00194-2.

18. Leili M, Mousavi SG, Nadafi K, Ghaffari M. The investigation of single ozonation process, catalytic ozonation process and single adsorption on activated carbon efficiencies for removal of furfural from aqueous solution. Journal of Sabzevar University of Medical Sciences 2013; 20(1): 51-61.

19. Ashori A, Hamzeh Y, Ziapour A. Application of soybean stalk for the removal of hazardous dyes from aqueous solutions. Polymer Engineering \& Science 2014; 54(1): 23945. doi: 10.1002/pen.23695.

20. Cetojevic-Simin DD, Armakovic SJ, Sojic DV, Abramovic BF. Toxicity assessment of metoprolol and its photodegradation mixtures obtained by using different type of $\mathrm{TiO} 2$ catalysts in the mammalian cell lines. Sci Total Environ 2013; 463464: 968-74. doi: 10.1016/j.scitotenv.2013.06.083.

21. Abramovic B, Kler S, Sojic D, Lausevic M, Radovic T, Vione D. Photocatalytic degradation of metoprolol tartrate in suspensions of two $\mathrm{TiO} 2$-based photocatalysts with different surface area. Identification of intermediates and proposal of degradation pathways. J Hazard Mater 2011; 198: 123-32. doi: 10.1016/j.jhazmat.2011.10.017.

22. Kibbey TC, Paruchuri R, Sabatini DA, Chen L. Adsorption of beta blockers to environmental surfaces. Environ Sci Technol 2007; 41(15): 5349-56. doi: 10.1021/es070152v.

23. Garala K, Patel J, Patel A, Dharamsi A. Enhanced encapsulation of metoprolol tartrate with carbon nanotubes as adsorbent. Appl Nanosci 2011; 1(4): 219-30. doi: 10.1007/ s13204-011-0030-3.

24. Daneshkhah M, Hossaini H, Malakootian M. Removal of metoprolol from water by sepiolite-supported nanoscale zero-valent iron. J Environ Chem Eng 2017; 5(4): 3490-9. doi: $10.1016 /$ j.jece.2017.06.040.

25. Ye Y, Feng Y, Bruning H, Yntema D, Rijnaarts HHM. Photocatalytic degradation of metoprolol by $\mathrm{TiO} 2$ nanotube arrays and UV-LED: Effects of catalyst properties, operational parameters, commonly present water constituents, and photo-induced reactive species. Appl Catal B Environ 2018; 220: 171-81. doi: 10.1016/j. apcatb.2017.08.040.

26. Yin L, Ma R, Wang B, Yuan H, Yu G. The degradation and persistence of five pharmaceuticals in an artificial climate incubator during a one year period. RSC Adv 2017; 7(14): 8280-7. doi: 10.1039/C6RA28351A.

27. Liu QT, Williams HE. Kinetics and degradation products for direct photolysis of beta-blockers in water. Environ Sci Technol 2007; 41(3): 803-10. doi: 10.1021/es0616130.

28. Moctezuma E, Leyva E, Lopez M, Pinedo A, Zermeno B, Serrano B. Photocatalytic degradation of metoprolol tartrate. Top Catal 2013; 56(18-20): 1875-82. doi: 10.1007/ s11244-013-0119-x.

29. Baek MH, Ijagbemi CO, O SJ, Kim DS. Removal of malachite green from aqueous solution using degreased coffee bean. J Hazard Mater 2010; 176(1-3): 820-8. doi: 10.1016/j.jhazmat.2009.11.110.

30. De Gisi S, Lofrano G, Grassi M, Notarnicola M. Characteristics and adsorption capacities of low-cost sorbents for wastewater treatment: a review. Sustainable Materials and Technologies 2016; 9: 10-40. doi: 10.1016/j. susmat.2016.06.002.

31. Bhatnagar A, Sillanpaa M, Witek-Krowiak A. Agricultural waste peels as versatile biomass for water purification-A review. Chem Eng J 2015; 270: 244-71. doi: 10.1016/j. cej.2015.01.135.

32. Zhou Y, Zhang L, Cheng Z. Removal of organic pollutants from aqueous solution using agricultural wastes: a review. J Mol Liq 2015; 212: 739-62. doi: 10.1016/j. molliq.2015.10.023.

33. Chen B, Yuan M, Liu H. Removal of polycyclic aromatic hydrocarbons from aqueous solution using plant residue materials as a biosorbent. J Hazard Mater 2011; 188(1-3): 436-42. doi: 10.1016/j.jhazmat.2011.01.114.

34. Mohseni SN, Amooey AA, Tashakkorian H, Amouei AI. Removal of dexamethasone from aqueous solutions using modified clinoptilolite zeolite (equilibrium and kinetic). Int J Environ Sci Technol 2016; 13(9): 2261-8. doi: 10.1007/ s13762-016-1045-9.

35. Bouyahmed F, Cai M, Reiuert L, Duclaux L, Dey KR, Ben Youcef $\mathrm{H}$, et al. A wide adsorption range hybrid material based on chitosan, activated carbon and montmorillonite for water treatment. Journal of Carbon Research 2018; 4(2): 1-11. doi: 10.3390/c400035.

36. Ahmed MJ, Theydan SK. Fluoroquinolones antibiotics adsorption onto microporous activated carbon from lignocellulosic biomass by microwave pyrolysis. J Taiwan Inst Chem Eng 2014; 45(1): 219-26. doi: 10.1016/j. jtice.2013.05.014.

37. Rivera-Utrilla J, Sanchez-Polo M, Prados-Joya G, FerroGarcia MA, Bautista-Toledo I. Removal of tinidazole from waters by using ozone and activated carbon in dynamic regime. J Hazard Mater 2010; 174(1-3): 880-6. doi: 10.1016/j.jhazmat.2009.09.059.

38. Basha S, Keane D, Morrissey A, Nolan K, Oelgemoller M, Tobin J. Studies on the adsorption and kinetics of photodegradation of pharmaceutical compound, indomethacin using novel photocatalytic adsorbents (IPCAs). Ind Eng Chem Res 2010; 49(22): 11302-9. doi: 10.1021/ie101304a. 